\title{
QUANDO O CORPO DÁ VIDA AOS OBJETOS: ANTROPOMORFISMO NA TRADUÇÃO PARA LÍNGUA BRASILEIRA DE SINAIS
}

\author{
WHEN THE BODY GIVES LIFE TO OBJECTS: ANTHROPOMORPHISM IN \\ TRANSLATION INTO BRAZILIAN SIGN LANGUAGE
}

\section{CUANDO EL CUERPO DA VIDA A LOS OBJETOS: ANTROPOMORFISMO EN LA TRADUCCIÓN DELA LENGUA BRASILEÑA DE SEÑALES}

\author{
Aline Ambrozio * \\ Simone Alencar ** \\ Valdinéia Nascimento ${ }^{* * *}$ \\ Neiva de Aquino Albres ${ }^{* * * *}$
}

\section{Resumo}

Este trabalho analisa o uso do antropomorfismo como estratégia tradutória do português para Libras do texto infantil Pedro e Tina, uma amizade muito especial, escrito e ilustrado por Stephen Michael King. Adotamos como metodologia o Estudo de Caso e como referencial teórico, foram usados textos de autores como Sutton-Spence e Napoli, McCleary e Viotti, Mattos, Pimenta e Andrade. Para a construção da narrativa em Libras, os tradutores foram motivados pelas ilustrações do livro, reorganizando a sinalização a partir da descrição, narração e incorporação de elementos visuais da história. As ilustrações colaboraram com o texto em Libras, contribuindo também para o estabelecimento dos referentes locais, posicionamento das personagens e características dos objetos antropomorfizados.

Palavras-chave: Literatura em Língua Brasileira de Sinais. Antropomorfismo. Tradutor/ator.

\footnotetext{
* Especialista em Tradução/Interpretação Libras/Português pelo Instituto Singularidades - SP. Tradutora/Intérprete de Libras/Português no IFSP. E-mail: anambrozio87@gmail.com

** Especialista em Tradução/Interpretação Libras/Português pelo Instituto Singularidades, SP. Tradutora/Intérprete de Libras/Português na UNIFESP. E-mail: simonecaldeiraalencar@gmail.com

*** Especialista em Tradução/Interpretação Libras/Português pelo Instituto Singularidades - SP. Professora dos cursos de Pedagogia, Educação Física e Letras do Centro Universitário Padre Anchieta (UniAnchieta) e Coordenadora Pedagógica junto à Diretoria de Educação Inclusiva do município de Jundiaí. E-mail: vit_val@yahoo.com.br
}

**** Doutora em Educação Especial. Docente e pesquisadora da UFSC vinculada ao programa de Pós-graduação em Estudos da Tradução - PGET UFSC. E-mail: neiva.albres@ufsc.br 


\section{Introdução}

Nos últimos anos houve um aumento significativo do número de obras literárias produzidas por surdos em Língua Brasileira de Sinais e de traduções de textos do Português para a Libras. Esse movimento se deu em virtude das Leis 10.436/02, 13.146/15 e do Decreto 5.626/05, que objetivam garantir direitos às pessoas surdas e, por consequiência, estimulam a produção de materiais bilíngues para lhes assegurar o acesso à informação, cultura e comunicação. Ainda assim, se comparado às publicações em Língua Portuguesa, o volume dessas obras é muito menor.

A literatura traduzida para a Libras é produzida por tradutores de Libras/Português e registrada em formato de CD-ROM ou DVD do seguinte modo: armazena-se em mídia um livro digital com o texto escrito, as imagens e o áudio em Português com uma janela de Libras (ROSA, KLEIN, 2012, p.3). O público consumidor desse material é formado por pessoas surdas e ouvintes que usufruem dessa literatura para estudar e apropriar-se da língua e da cultura surda (MOURÃO, 2011).

O processo de criação de materiais traduzidos do português para Libras exige pesquisa, gravação e revisão do produto final (MOURÃO, 2011). No Brasil, algumas obras literárias foram traduzidas, e as pesquisas científicas sobre esses produtos se iniciam, visando aperfeiçoar e garantir qualidade para as novas produções. Pesquisas sobre a tradução para a Libras indicam que o tradutor fica em evidência no vídeo-livro e interpreta o texto como um ator, porque empresta o seu corpo para representar o cenário, personagens e o enredo como todo, no momento de sua atuação, como afirma Andrade (2015, p. 45) ao usar o termo tradutor/ator. Quando se trata de tradução literária, como poesia, fábulas, contos e lendas, muitas vezes o tradutor/ator precisa utilizar o recurso do antropomorfismo, com o objetivo de produzir um texto viso-espacial rico em recursos imagéticos, dinâmico, criativo, coerente e atrativo para o público leitor.

O objetivo deste trabalho é analisar o uso de antropomorfismo em línguas de sinais, na tradução coletiva da obra de literatura infanto-juvenil Pedro e Tina: uma amizade muito especial, de Stephen Michael King, em um curso de Tradução/Interpretação Libras/Português, trazendo reflexões sobre o uso de antropomorfismo no processo de tradução para a Libras de uma obra de Literatura Infantil e sobre a responsabilidade de se usar estratégias de tradução que respeitem a língua, as normas de tradução e a cultura surda. As questões iniciais que se colocam nesta pesquisa são: Quando o antropomorfismo foi utilizado na tradução do livro de 
Stephen King? Que elementos presentes na obra motivaram os tradutores a usar esse recurso de tradução?

\section{Sobre Línguas de Sinais e tradução}

A Libras é uma língua de modalidade visual-espacial. Seu canal de comunicação é o corpo do sujeito que enuncia (face, tronco e mãos) e as percepções de enunciados se dão pela visão (ALBRES; COSTA; ROSSI, 2015). Por conseguinte, os interlocutores do discurso precisam estar face a face, para que haja interação e a enunciação é feita num espaço de sinalização, "por meio da articulação das mãos e das expressões faciais corporais ou sinaislinguísticos não manuais, dêiticos ou anafóricos, direcionamento do olhar, movimento do corpo, articulação de sinais concomitantes, mecanismos de coesão e coerência" (PASSOS, 2009, p. 50). De acordo com Albres, Costa e Rossi, a enunciação, nas línguas sinalizadas,

[...] se dá por meio do corpo (face, tronco, mãos) [...] o uso de sinais não manuais marcando as mudanças de vozes narrativas, que passam do narrador para o personagem e que também contribuem para a construção de sentido do cenário. [...] uso do conceito de espaço sub-rogado, que é resultado da integração do espaço real com um espaço do evento $(2015$, p. 6).

Assim, no processo de enunciação o tradutor pode, com seu corpo, expressar-se como o narrador, como os personagens ou representando objetos inanimados (o que é chamado de antropomorfismo). São as narrativas populares que, pouco a pouco, compõem a literatura de um povo, colaborando com a construção de sua cultura. A Literatura Surda, segundo Mourão,

[...] traz histórias de comunidades surdas, os processos sociais e as práticas relacionadas que circulam em diferentes lugares e em diferentes tempos. O envolvimento que as comunidades surdas compartilham, não é somente interno à comunidade, mas também externo, com comunidades ouvintes tanto de sujeitos ouvintes quanto de sujeitos surdos $(2011$, p.50).

Esse tipo de texto apresenta características singulares, próprias do povo surdo, como a valorização das percepções e interações visuais com o mundo; o uso da Língua de Sinais; costumes da cultura surda; produções culturais independentes da cultura ouvinte. Strobel identifica textos de literatura surda como "histórias que têm a língua de sinais, a identidade e a cultura surda presentes na narrativa" (2013, p.44). Quanto à literatura surda, Strobel a define como "a produção de textos literários em sinais, que traduz a experiência visual, que entende a surdez como presença de algo e não como falta, que possibilita outras representações de 
surdos e que considera as pessoas surdas como um grupo linguístico e cultural diferente" (2013, p. 44).

Atualmente, parte das narrativas em Libras são filmadas e gravadas em mídias físicas como CD-ROM, DVD (MOURÃO, 2011, p. 68), ou armazenadas em espaços virtuais, como as redes sociais, o YouTube, o Facebook, Sites, Blogs, entre outros (ROSA; KLEIN, 2012, p.3). A literatura traduzida para Libras é composta a partir de obras escritas em Língua Portuguesa, traduzidas ou adaptadas para Libras.

\begin{abstract}
A tradução palavra-por-palavra, do português para a Libras corresponde ao que chamamos de "português-sinalizado", que na grande maioria das situações é inadequado às necessidades enunciativas produtoras de sentido nas línguas de sinais [...] há grande possibilidade de o interlocutor surdo não entender, tornando a enunciação mecânica e artificial. [...] poderíamos verificar inúmeros equívocos de sentido (SANTIAGO, 2012, p. 39 e 40).
\end{abstract}

Esse tipo de tradução, feita palavra por palavra, pode ter falhas, além de problemas relacionados a entendimento e compreensão. Segundo Mourão, geralmente,

[...] não ocorre uma tradução literal, palavra por palavra, mas uma interpretação ou tradução, para que as pessoas que usam uma língua possam compreender e interpretar os processos sociais que se desenvolvem em outra língua, em uma outra cultura [...]. Importante é que os tradutores/intérpretes de língua de sinais conheçam o sentido e contexto das palavras (sinais), com conhecimento da cultura surda e com participação social na comunidade surda, enfim dentro do círculo surdo (2011, p.63 e 65).

Sendo assim, os que pretendem traduzir textos narrativos precisam, segundo Albres, Costa e Rossi, "se apropriar das formas de dizer em contextos de contação de histórias, levando em consideração o público alvo do material produzido, formas outras de dizer tanto no texto fonte quanto no texto da tradução" $(2015$, p.2).

Mourão (2011, p.65) observa que, atualmente, há traduções de clássicos da literatura disponíveis em forma de DVDs, pela Editora Arara Azul, como Iracema (2002); Alice no País das Maravilhas (2002); As Aventuras de Pinóquio (2003); O Alienista (2004). Tem-se ainda outras obras, como O caso da Vara (2005), A ilha do tesouro (2008), O cortiço (2015) e as publicações da editora Brinque-book, Ciranda Cultural, com Contos Clássicos em Libras (2010).

Após pesquisarmos a quantidade de obras já traduzidas de Língua Portuguesa para Libras, em sites de editoras e trabalhos acadêmicos, nota-se que, em concordância com Andrade (2015), há uma pequena quantidade de livros disponíveis em Língua de Sinais para o 
público surdo. Bassnett e Trivedi (1991, p. 14) observam que, no corpo da cultura, a língua é o coração. Da interação entre língua e cultura, resulta a continuação de sua energia-vital. Da mesma forma que o cirurgião, operando o coração, não pode desconsiderar o corpo que o abriga, o tradutor não pode isolar o texto da cultura que o recebe.

É necessário, portanto, no processo de tradução, não desvincular o texto da cultura do povo que o produziu. Importantes também são as habilidades, a competência linguística, culturais e tradutórias para desenvolver tal função, uma vez que, o material traduzido pode ser usado tanto por pessoas surdas, como por ouvintes, em processo de aquisição de linguagem, ou ainda, como modelo linguístico, cultural, social, pois as obras literárias trazem consigo valores, costumes, tradições e características específicas do povo que as concebe.

\section{Antropomorfismo: referencial teórico}

A figura de estilo, ou tropo, denominada "antropomorfismo", é muito comum em narrativas infantis. Esse termo é oriundo da língua grega, reunindo os conceitos de anthropos (homem) e morphe (forma), o que sugere a expressão "forma humana". Trata-se de um fenômeno que não ocorre exclusivamente nas Línguas de Sinais. Segundo Andrade (2015), o conceito de antropomorfismo é semelhante ao da prosopopéia. Nas traduções para Línguas de Sinais, o antropomorfismo pode ser compreendido como um recurso usado para dar características humanas a animais ou a objetos inanimados, podendo o tradutor atuar enquanto ator, na tradução de textos literários. A ação de "dar forma humana", contudo, não deve ser confundida com a "incorporação do objeto", pois ela vai além, ao atribuir sentimentos e aspectos culturais que são próprios do ser humano.

A distinção conceitual entre estes dois fenômenos, o "antropomorfismo" e a “incorporação do objeto" pode ser compreendida a partir dos seguintes exemplos: em uma narrativa um animal, ao ser incorporado, poderá demonstrar tristeza, mas se ele disser que está se sentindo triste, essa atuação deixa de ser incorporação e passa a ser antropomorfismo, visto que expressar sentimentos verbalmente é uma capacidade somente dos seres humanos. Outra situação diz respeito a algum objeto que se move e, de alguma forma, se comunica, expressando sentimentos. Esse é um objeto antropomorfizado, uma vez que em objetos ou seres inanimados esse comportamento não seria possível.

O antropomorfismo pode ocorrer na sinalização propriamente dita, mas também envolve as expressões faciais. O corpo do sinalizador age como personagem e sua face pode expressar pensamentos e sentimentos, com a direção do olhar indicando, em certos momentos, 
uma mudança de ponto de vista. Nas histórias em que ocorre o antropomorfismo, o surdo tem a possibilidade de se identificar, de ver no outro alguns aspectos de sua própria identidade e, nessa relação, ele pode se nutrir, pois o ser antropomorfizado, segundo Andrade (2015) apresentará aspectos culturais surdos, desde que o trabalho seja bem realizado. De acordo com Vieira (2016) esse é um importante recurso, usado para que se possa comunicar algo metaforicamente.

O tradutor/ator deve estar consciente da importância do seu trabalho como modelo linguístico para o público leitor, pois sua produção de traduções de textos do Português (escrito) para a Língua de Sinais será, certamente, referência para o seu público de surdos e ouvintes. Segundo McCleary e Viotti “o modo de fazer do contador da história, ou seja, as expressões não manuais, posicionamento do corpo, imprimem marcas estilísticas ao discurso que, interferem no modo como esta narrativa chega ao interlocutor" (2014, p.124). Para esta pesquisa, foram utilizados, como referencial teórico obras que, de alguma forma, se debruçaram sobre o tema do antropomorfismo nas narrativas em Línguas de Sinais.

Pimenta (2012) em A tradução de fábulas seguindo aspectos imagéticos da linguagem cinematográfica e da língua de sinais demonstra como a linguagem cinematográfica e as narrativas das fábulas em Língua de Sinais podem ser relacionadas em aspectos de construção imagética para:

[...] tornar uma narrativa menos operativa ou informativa e mais expressiva segundo Baker (1992) e, consequentemente, mais inteligível para um surdo pela concordância entre a natureza visual dos surdos e as práticas narrativas de construção imagética e que certamente ao serem postos em prática em traduções de fábulas do português para a língua de sinais possibilitará a formação de significados na narrativa pelos surdos, cumprindo então o objetivo das fábulas na formação do conjunto de valores que vão constituir os indivíduos como sujeitos inseridos em uma cultura (PIMENTA, 2012, p.60).

A dissertação de Andrade (2015) A tradução de obras literárias em língua brasileira de sinais - antropomorfismo em foco discorre sobre a educação de surdos na perspectiva bilíngue, afirmando que um dos desafios desta proposta, é a escassez de materiais didáticos traduzidos para Libras. Andrade (2015) investiga vídeos de obras literárias infantis em Libras e faz análises das estratégias de antropomorfismo usadas pelos tradutores/autores surdos. Segundo a autora, o uso de antropomorfismo deixa o texto mais atrativo, divertido e agradável para a criança surda, pois ela se identifica com as personagens, contribuindo para o seu desenvolvimento de linguagem. 
Andrade analisa como o tradutor/ator contribui com sua experiência cultural surda, seguindo uma norma surda de tradução (STONE, 2009). Com base em Jakobson (1975), avalia o trabalho na tradução interlingual do português escrito para Libras; a tradução intermodal, entre duas modalidades diferentes (SEGALA, 2010); a tradução intersemiótica (JAKOBSON, 1975) visual/vídeo e a tradução etnocêntrica (BERMAN, 2013), cultural, em que é possível traduzir a cultura surda de acordo com a cultura da língua alvo.

McCleary e Viotti (2014) em Espaços integrados e corpos partidos: vozes e perspectivas narrativas em línguas sinalizadas discutem a necessidade de os estudos da narrativa darem mais importância à investigação de narrativas face a face; a importância de como o tradutor particiona ${ }^{1}$ o corpo para organizar o espaço de sinalização; a definição de quais elementos podem ser usados na construção da narrativa (sinais dêiticos, manuais, não manuais, mecanismos de coesão e coerência, uso de espaço sub-rogado para representar o cenário, as personagens e narrador - mudança de vozes , ações, fatos, significação). Além disso, os autores sinalizam para a necessidade de se promover discussões sobre teorias como as de construção dinâmicas de discurso e construção de espaços mentais.

Mattos (2013) em Antropomorfismo na Cultura da Animação, embora não se refira à língua de sinais, aborda as influências artísticas e ideológicas no uso do antropomorfismo em filmes tchecos. Inicia seu estudo fazendo um percurso histórico do uso do antropomorfismo desde os primeiros tempos da civilização nas histórias contadas de geração e geração. Em seguida, faz análises das diferentes técnicas e estudos de animação de criações antropomórficas em produções audiovisuais.

\section{Metodologia da pesquisa}

Esta pesquisa, na qual analisamos a tradução do livro Pedro e Tina, uma amizade muito especial, da editora Brinque-Book, escrito e ilustrado por Stephen Michael King (1999), que foi desenvolvida em curso de formação de tradutores, configura-se como de abordagem qualitativa, de cunho descritivo-analítico, baseada na perspectiva sócio-histórica, de acordo com Freitas (2002).

O corpus desta pesquisa foi produzido em um contexto natural de ensinoaprendizagem, caracterizando-se como uma prática de tradução coletiva, orientada por um dos autores deste artigo, que poderá ser útil para o estudo de práticas tradutórias para a Libras no gênero narrativo. Para Baker, o corpus "tem um papel importante a desempenhar na exploração de normas de tradução e em contextos específicos socioculturais e históricos" 
(1995, p. 231, tradução nossa) ${ }^{2}$ O corpus deste trabalho é caracterizado por ser bilíngue, sincrônico, especializado e unidirecional, de acordo com o proposto por Fernandes (2004).

Tabela 1 - Classificação do corpus

\begin{tabular}{|l|l|}
\hline \multicolumn{1}{|c|}{ Critério } & \multicolumn{1}{c|}{ Caracterização } \\
\hline a) número de línguas & Bilíngue (português e Libras) \\
\hline b) restrição temporal & Sincrônico (análise da tradução da obra "Pedro e Tina" - 2016) \\
\hline c) domínio & Especializado - literatura infanto-juvenil - gênero narrativo \\
\hline d) direcionalidade & $\begin{array}{l}\text { Unidirecional (em que é observada a tradução de Português para } \\
\text { Libras) }\end{array}$ \\
\hline
\end{tabular}

Fonte: Adaptado de Fernandes (2004).

$\mathrm{Na}$ análise da obra procurou-se determinar quais elementos motivaram os tradutores a usar o antropomorfismo na tradução do livro Pedro e Tina: uma amizade muito especial. Foram avaliados os aspectos antropomórficos da Libras das páginas 28 e 29 da obra analisada. Nos momentos em que há uso do antropomorfismo, adotamos o esquema de organização proposto por Albres (2014), com a decupagem ${ }^{3}$ e a glosa seguindo abaixo das imagens.

Apresentamos a imagem e texto do livro (texto de partida) e a decupagem do corpo do tradutor com frames da tradução (enquadres da sinalização do vídeo). Estes frames foram nomeados pela letra $\mathrm{T}$ (de tradução) e receberam numeração crescente. Para a transcrição da tradução em Libras, os sinais convencionados da língua foram apresentados em caixa alta; os gestos e incorporação entre parênteses descrevem a encenação quando necessário.

\section{Estratégias de tradução}

A proposta desta seção é descrever as estratégias utilizadas na tradução, observando como os tradutores construíram o antropomorfismo em Libras na obra de literatura infantil Pedro e Tina: uma amizade muito especial, escrito e ilustrado por Stephen Michael King. 
Figura 1 - Página do livro analisado neste artigo.

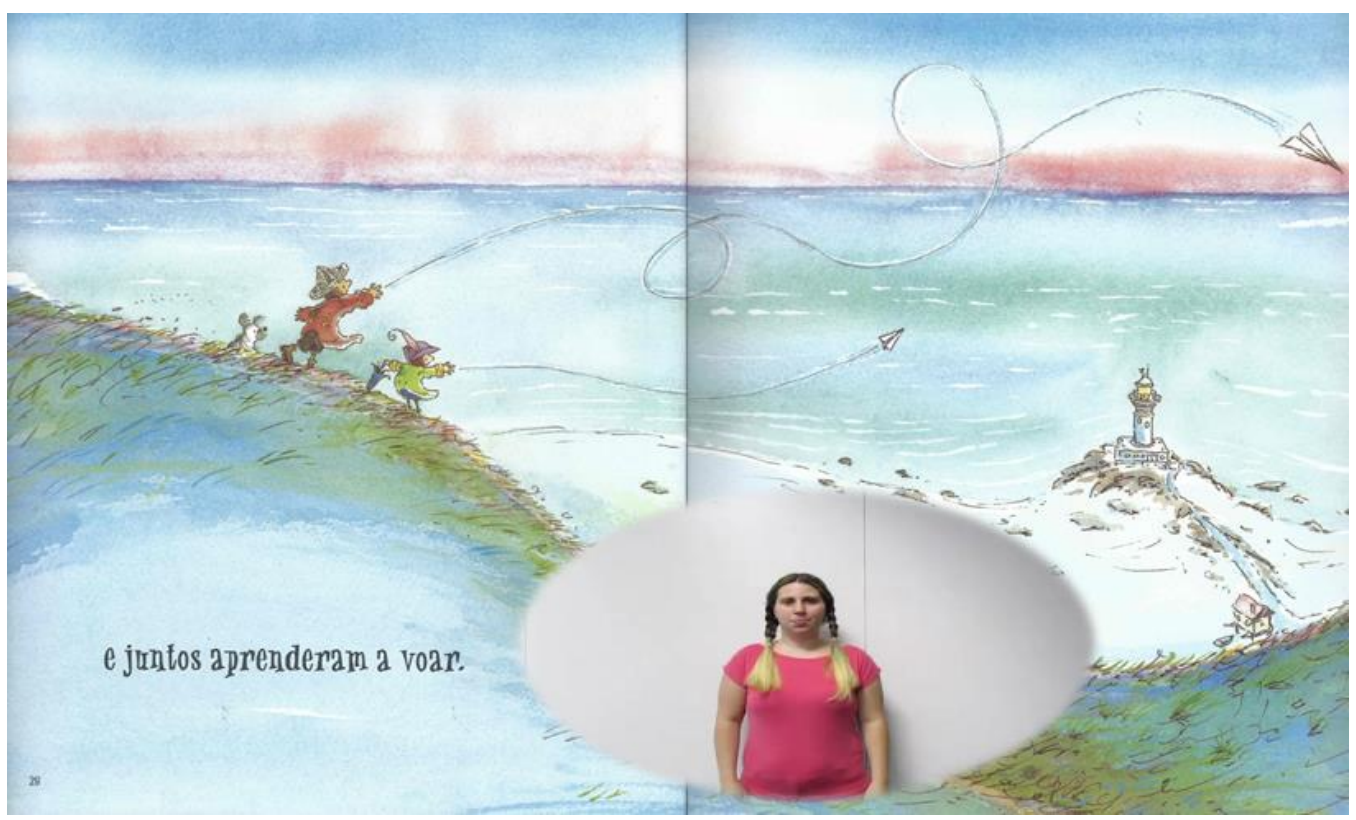

Fonte: Adaptação de KING (2005, p. 38-39)

Na Figura 1, apresentamos duas das páginas do livro traduzido coletivamente para Libras e executado por uma tradutora. As duas personagens, Pedro e Tina, seguem em suas aventuras, aprendendo um com o outro e, nesse trecho da história, brincam de lançar aviões de papel. Além do texto em português, há também a ilustração, que ocupa as duas páginas. Vê-se um monte de areia, onde estão as personagens, e mais adiante o mar, onde se ergue um farol. A cor azul predomina tanto no céu e no mar como também na terra.

A tradução para Libras, exposta na Figura 2, procurou abranger esse todo semiótico: o texto em português "e juntos aprenderam a voar" e a ilustração que apresenta a paisagem:

Figura 2 - Frame da tradução e glosa

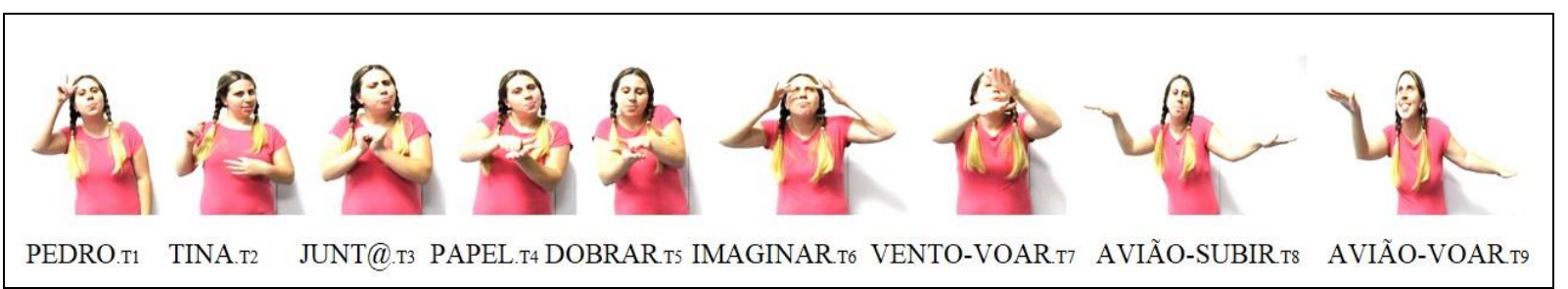

Dividimos esse trecho da tradução em duas partes. Na primeira, do sinal T1 a T5, a tradutora informa ao leitor que Pedro e Tina estavam juntos, pegaram um papel e o dobraram. 
Na segunda parte, do sinal T6 a T9, a tradutora corporifica o avião de papel ao deixar-se livre para a imaginação e solta o corpo, como se estivesse a voar.

É possível observar que a construção da tradução foi motivada pela ilustração e pelo texto. Entre T4 a T6 a tradutora utiliza sinais que não correspondem necessariamente ao referente mencionado no texto em português, mas aos elementos não verbais contidos na ilustração, ou seja, os aviões de papel com os quais as personagens brincam.

Na imagem T7 a tradutora representa, com o seu corpo, as características de um avião, reproduzindo o movimento e a leveza do voo imaginário de Pedro e Tina. Nas imagens de T8 e T9, com o avião em pleno voo, observa-se a ocorrência do antropomorfismo, pois a tradutora não só representa com seu corpo o objeto inanimado, como também imprime expressões faciais e direção ao olhar, o que não seria possível para um objeto, a não ser pela ocorrência do antropomorfismo, pois nas Línguas de Sinais as expressões faciais carregam informações afetivas e gramaticais, o que inclui intensidade. Andrade (2015) observa que:

No antropomorfismo sinalizado, na personificação de entidades surdas, os olhos são importantes, para poder visualizar o mundo de forma surda. Também a expressão facial é importante, porque permite que a entidade representada possa mostrar emoção ou até mesmo informações gramaticais (ANDRADE, 2015, p.81).

Nesses recortes de texto são perceptíveis os elementos extralinguísticos da narrativa, os quais contribuem para a construção do sentido a partir da tradução, considerando que o corpo do tradutor compõe o novo material multimodal. O sentido desse texto pode ser compreendido metaforicamente, com os personagens/crianças tomando a forma do avião de papel e se lançando aos desafios da vida, de peito aberto para a aprendizagem. Pelo uso da linguagem é possível propiciar no leitor diferentes possibilidades de interpretação. Culturalmente, na Libras, a incorporação das personagens e o uso de voz direta são usuais, ocorrendo também na representação de objetos inanimados. A estratégia do antropomorfismo, segundo Sutton-Spence e Napoli (2010, p.442) passa pela atribuição de aparências e de sentimentos, próprios de seres humanos, a seres animados ou inanimados.

No trecho da tradução analisada, é possível notar esse aspecto quando o tradutor corporifica a ação de voar do avião de papel por meio da movimentação das mãos e pela inclinação do corpo para um lado e para o outro. Apresentamos, a seguir, de forma mais detalhada, a tradução de T7 a T9. 
Figura 3 - Frame da tradução e glosa

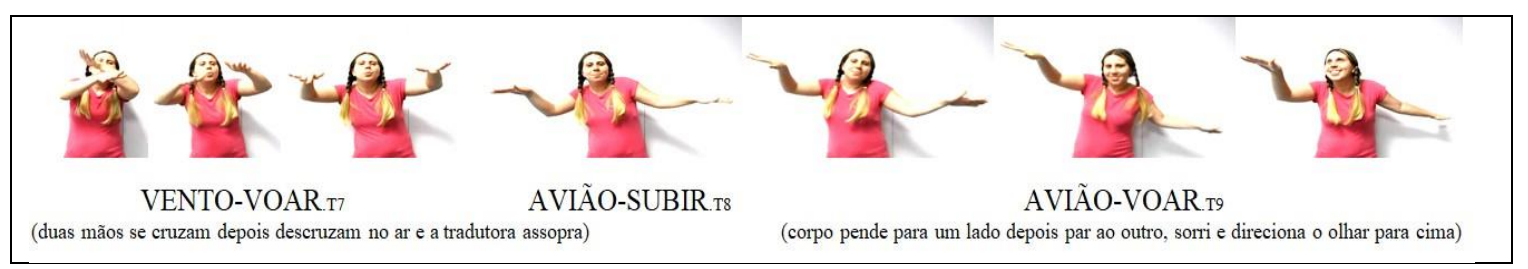

Retomando a ilustração de King, verificamos que o T7 foi motivado pela imagem dos dois aviões de papel. Cada mão da tradutora representa um dos aviões de papel, enquanto ela assopra, indicando o vento que os ergue e conduz. No T8, a tradutora faz a transição dessa representação do avião, passando das mãos para o corpo e assumindo a projeção de si mesma, como o avião ao tomar uma rota. Em T9, ela faz manobras com o corpo, para um lado e para o outro, como se fosse o avião de papel.

Exatamente aqui se revelam: a interface entre a língua como acontecimento, a tradução como autoria e escolhas particulares, e ainda, a literatura como construção social e histórica. Mesmo quando a literatura é traduzida, recriada em outra língua, a cultura do público alvo deve aflorar e preceder qualquer visão prescritiva de culto à forma do texto de partida. Destacamos que nem todos os elementos inanimados ou animais que faziam parte da história foram antropomorfizados, uma vez que cada tradutor faz suas escolhas.

\section{Considerações finais}

Neste trabalho foi possível constatar que a tradução para Línguas de Sinais se faz em diferentes gêneros discursivos e que a tarefa do tradutor de obra de literatura infanto-juvenil apresenta inúmeros desafios, dentre os quais destacamos o trabalho com material multisemiótico. É na totalidade dos enunciados (verbais e visuais) apresentados no texto de partida que o tradutor se sente provocado para a produção dos enunciados na Língua de Sinais.

Para a construção da narrativa em Libras, os tradutores foram motivados pelo todo semiótico do material da obra analisada, ou seja, pelo texto em português escrito e pelo texto sugerido pelas imagens da ilustração. A sinalização foi reorganizada, descrevendo, narrando e incorporando elementos da história. Verificamos que, nesse tipo de texto, a ilustração pode determinar o texto em Línguas de Sinais, valorizando, na tradução, aspectos da construção imagética e características dos objetos antropomorfizados ${ }^{4}$. 
Descrevemos a incorporação de um avião de papel que é lançado de um penhasco, tendo o céu azul e o mar ao fundo. No decorrer da análise das imagens do material traduzido para Língua de Sinais, percebeu-se que o antropomorfismo foi utilizado a fim de traduzir metaforicamente para a Libras uma figura de linguagem para a palavra "voar", que representa o imaginário das personagens. Assim, a literatura, como uma forma de expressão da língua, está imbuída da cultura e das formas que lhe são próprias.

\begin{abstract}
In this work we analyze the use of anthropomorphism as a translation strategy from Portuguese to Libras of the children's text Pedro and Tina, a very special friendship written and illustrated by Stephen Michael King. Case Study was adopted as methodology, and texts by Sutton-Spence e Napoli, Pimenta, McCleary, Viotti, Mattos and Andrade were used as theoretical reference,. For the construction of the narrative in Libras, the translators were motivated by the illustrations of the book, reorganizing the signage based on the description, narration and incorporation of visual elements of story. The illustrations collaborated with the text in Libras, also contributing to the establishment of local referents, positioning of the characters and characteristics of the anthropomorphized objects.
\end{abstract}

Keywords: Literature in Brazilian Sign Language. Anthropomorphism. Translator/actor.

\title{
Resumen
}

En este trabajo se analiza el uso del antropomorfismo como la estrategia de traducción del portugués para LIBRAS del texto infantil en portugués Pedro e Tina, uma amizade muito especial, escrito e ilustrado por Stephen Michael King. La metodología utilizada fue el Estudio de Caso y, como referencial teórico, se utilizaron textos de Sutton-Spence y Napoli, McCleary y Viotti, Mattos, Pimenta y Andrade. Para la construcción de la narrativa en LIBRAS, los traductores fueron incentivados por las ilustraciones del libro, reorganizando la señalización a partir de la descripción, narración e incorporación de los elementos visuales. Las ilustraciones colaboraron con el texto en LIBRAS, también para el establecimiento de los referentes locales, posicionamiento de los personajes y características de los objetos antropomorfizados.

Palabras-clave: Literatura en Lengua Brasileña de Señales. Antropomorfismo. Traductor / actor.

\section{Referências}

ALBRES, N. A.. "Tradução de Literatura Infanto-Juvenil para Língua de Sinais: dialogia e polifonia em questão". p. 1151-1172, em RBLA, Belo Horizonte, v. 14, n. 4, 2014. Disponível em: http://www.scielo.br/pdf/rbla/2014nahead/aop6014.pdf . Acesso em: 20 abr. 2018. 
ALBRES, N. A.; COSTA, M. P.P.; ROSSI, T. W. T.. "Gesto-visualidade no processo de tradução de Literatura Infanto-Juvenil: marcas do discurso narrativo", Revista Translatio, Universidade Federal do Rio Grande do Sul, 2015. Disponível em: <http://seer.ufrgs.br/index.php/translatio/article/view/51669>. Acesso em: 20 abr. 2018.

ANDRADE, B. L.. A tradução de obras literárias em Língua Brasileira de Sinais: Antropomorfismo em foco. Dissertação de mestrado. Universidade Federal de Santa Catarina. Programa de Pós-Graduação em Estudos da Tradução, 2015. Disponível em: $<$ https://repositorio.ufsc.br/bitstream/handle/123456789/158455/336868.pdf?sequence $=1 \&$ isA llowed=y >. Acesso em: 23 abr. 2018.

BAKER, M. "Corpora in translation studies: An overview and some suggestions for future research" In:. Target, v. 7, n. 2, p. 223-243, 1995.

BASSNET, S.; TRIVEDI, H. Translation Studies. London/New York: Routledge, 1991.

BERMAN, Antoine. A tradução e a Letra ou o Albergue do Longínquo. Tradução de Marie-Hélène C. Torres, Mauri Furlan, Andreia Guerini. Florianópolis: Copiart/ PGETUFSC, 2013. Disponível em:

https://repositorio.ufsc.br/xmlui/bitstream/handle/123456789/178888/Antoine_Berman-

Traducao_e_a_Letra_2a\%20ed_2013.pdf?sequence $=1 \&$ isAllowed $=\mathrm{y}>$. Acesso em: 23 abr. 2018.

BRASIL. Lei $\mathrm{n}^{\circ}$ 10.436, de 24 de abril de 2002. Dispõe sobre a Língua Brasileira de Sinais - Libras e dá outras providências. Brasília, DF, 25 abr. 2002. Disponível em: http://www.planalto.gov.br/ccivil_03/leis/2002/L10436.htm. Acesso em: 10 jun. 2017.

. LEI N ${ }^{\circ}$ 13.146, DE 6 DE JULHO DE 2015. Dispõe sobre a Lei Brasileira de Inclusão da Pessoa com Deficiência. Disponível em: <http://www.planalto.gov.br/ccivil_03/Ato2015-

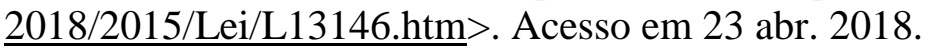

Decreto $n^{\circ}$ 5.626, de 22 de dezembro de 2005. Regulamenta a Lei $\mathbf{n}^{\mathbf{0}} \mathbf{1 0 . 4 3 6}$, de 24 de abril de 2002, que dispõe sobre a Língua Brasileira de Sinais - Libras. Brasília, DF, dez. 2005. Disponível em: http://www.planalto.gov.br/ccivil_03/_ato20042006/2005/decreto /d5626.htm. Acesso em: 10 abr. 2018.

FERNANDES, L. P. Practices of Translating Names in Children's Fantasy Literature: a corpus-based study. Florianópolis, 189 f. Tese (Doutorado) - Universidade Federal de Santa Catarina, Centro de Comunicação e Expressão, 2004. Disponível em: <http://repositorio.ufsc.br/xmlui/handle/123456789/87995>. Acesso em: 23 abr. 2018

JAKOBSON, Roman. Aspectos Linguísticos da Tradução. Tradução de Izidoro Blikstein e José Paulo Paes. São Paulo: Cultrix, 1975.

KING, Stephen Michael. Pedro e Tina, uma amizade muito especial, São Paulo: BrinqueBook, 1999. 
FREITAS, Maria Teresa de Assunção. "A abordagem sócio-histórica como orientadora da pesquisa qualitativa". Cadernos de Pesquisa. n.116, pp.21-39, 2002. Disponível em: <http://dx.doi.org/10.1590/S0100-15742002000200002>. Acesso em 23 abr. 2018.

McCLEARY, L.; VIOTTI, E.. "Espaços Integrados e Corpos Partidos: Vozes e Perspectivas Narrativas em Línguas Sinalizadas". Scripta, PUC Minas, Belo Horizonte, v. 18, n. 34, 2014. Disponível em: <http://periodicos.pucminas.br/index.php/scripta/article/view/P.2358-3428. 2014v18n34p121> Acesso em: 23 abr. 2018.

MATTOS, A. A. J.. Antropomorfismo na Cultura da Animação. Dissertação. Universidade Federal Fluminense. Programa de Pós-Graduação em Estudos Contemporâneos da Arte. Niterói, RJ, 2013. Disponível em: <www.artes.uff.br/dissertacoes/2013/alexandrejuruena.pdf>. Acesso em: 23 abr. 2018.

MOURÃO, C. H. N. Literatura surda: produções culturais de surdos em língua de sinais. Universidade Federal do Rio Grande do Sul, 2011. Disponível em: https://www.lume.ufrgs.br/bitstream/handle/10183/32311/000785443.pdf?sequence=1>

Acesso em 23 abr. 2018.

PASSOS, G. A. G.. "Mecanismos de coesão textual visual em uma narrativa sinalizada: língua de sinais brasileira em foco". In: QUADROS, Ronice Müller; STUMPF, Marianne Rossi (organizadoras). Estudos Surdos IV. - Petrópolis, RJ: Arara Azul, 2009.

PIMENTA, Nelson. A Tradução de Fábulas Seguindo Aspectos Imagéticos da Linguagem Cinematográfica e da Língua de Sinais. Universidade Federal de Santa Catarina. Programa de Pós-Graduação em Estudos da Tradução. 2012. Disponível em: <http://repositorio.ufsc.br/xmlui/handle/123456789/100721>. Acesso em: 23 abr. 2018.

ROSA, Fabiano Souto; KLEIN, Madalena. Literatura Surda: Marcas Surdas Compartilhadas, XI Encontro de Pós-Graduação (ENPOS) e a I Mostra Científica da Universidade Federal de Pelotas (UFPel), 2012. Disponível em: http://wp.ufpel.edu.br/fabianosoutorosa/files/2012/04/CIC-2009-UFPel.pdf. Acesso: 23 abr. 2018.

SANTIAGO, V. A.. "Português e Libras em Diálogo: os Procedimentos de Tradução e o Campo do Sentido", In: ALBRES, Neiva de A.; SANTIAGO, Vânia de A. Libras em Estudo: Tradução e Interpretação. São Paulo: Feneis, 2012.

SEGALA, Rimar. Tradução Intermodal e Intersemiótica/Interlingual: Português Brasileiro Escrito para a Língua Brasileira de Sinais, 2010. Dissertação (mestrado). Programa de Pós-Graduação em Estudos da Tradução. UFSC. Disponível em: http://repositorio.ufsc.br/xmlui/handle/123456789/94582. Acesso em: 23 abr. 2018.

STONE, C. Toward a Deaf Translation Norm. Washington-DC, USA, Gallaudet University Press, 2009.

STROBEL, K. As imagens do outro sobre a cultura surda. Florianópolis: Editora da UFSC, 2013. 
SUTTON-SPENCE, R; NAPOLI D.. "Anthropomorphism in Sign Languages: A Look at Poetry and Storytelling with a Focus on British Sign Language”, 2010. In: Sign Language Studies Vol. 10, No. 4, Summer 2010. Disponível em: 〈https://muse.jhu.edu/article/383400>. Acesso em: 23 abr. 2018.

VIEIRA, Saulo. Z.. A Produção Narrativa em Libras: Uma Análise dos Vídeos em Língua Brasileira de Sinais e da sua Tradução Intersemiótica a Partir da Linguagem Cinematográfica. Programa de Pós-Graduação em Estudos da Tradução, 2016. Disponível em: 〈https://repositorio.ufsc.br/xmlui/handle/123456789/175315>. Acesso em 23 abr. 2018.

\section{Notas}

\footnotetext{
${ }^{1}$ O particionamento do corpo, fenômeno próprio das línguas de sinais, ocorre em "dois níveis de integração conceitual com o corpo do enunciador, ora funcionando como narrador, ora como personagem, ora partido, realizando simultaneamente as duas funções” (McCLEARY, VIOTTI, 2014, p.10).

2 [...] they also have an important role to play in exploring norms of translating in specific socio-social and historical contexts.

${ }^{3}$ Decupagem é a sequência de imagens congeladas do contínuo de sinalização extraído de um vídeo em Libras. A decupagem é uma forma de registrar em suporte de papel (relatório de pesquisa - em programa Word) detalhadamente a sequência de enquadres dos sinais, contendo a movimentação do corpo do sinalizador, direção do olhar e a sequência de sinais manuais da tradução para língua gestual-visual.

4 Trabalho apresentado em comunicação oral no $7^{\circ}$ SIL - Seminário Internacional de Linguística, realizado na Universidade Cruzeiro do Sul Campus Anália Franco. São Paulo. 15 a 17 de setembro de 2017.
} 